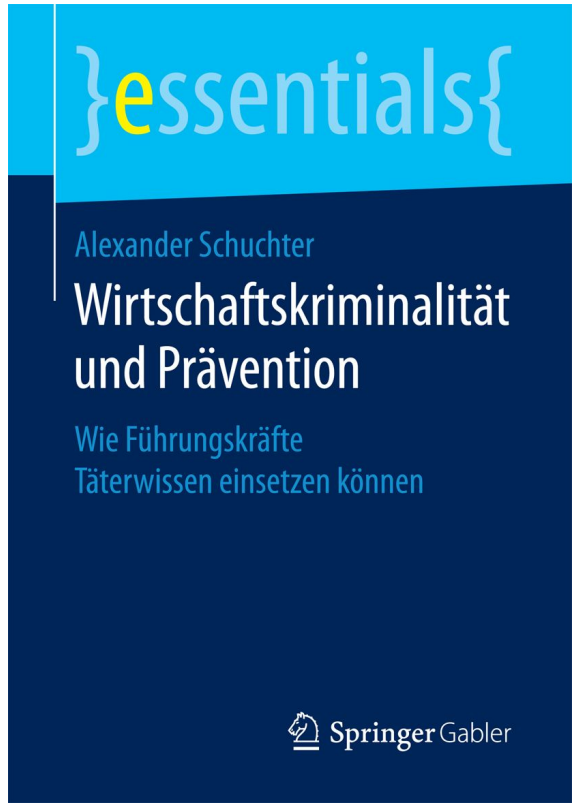

1. Aufl. 2018, XI, 46 S. 1 Abb.

\section{Gedrucktes Buch}

Softcover

[1] $9,99 €(D)|10,27 €(A)| C H F$

10,50

eBook

${ }^{[2]} 4,99 €(D)|4,99 €(A)|$ CHF 6,00

Erhältlich bei Ihrer Bibliothek oder

springer.com/shop
Alexander Schuchter

\section{Wirtschaftskriminalität und Prävention}

Wie Führungskräfte Täterwissen einsetzen können

\section{Reihe: essentials}

- Derzeitige Entwicklungen in der Wirtschaftskriminalität

- Neuer Ansatz durch die Aneignung

Das essential zeigt praxisnah, wie Haftungs-, Vermögens- und Reputationsrisiken, die mit Wirtschaftskriminalität einhergehen, gesenkt werden. Die Vorgehensweise der Täter verstehen zu lernen, verschafft den entscheidenden Vorsprung bei der Entwicklung unternehmensinterner Erkennungs- und Abwehrsysteme. Den Leser erwarten praxisrelevante Inhalte und Auszüge aus Interviews mit Wirtschaftsstraftätern, sprich „aus dem Nähkästchen Geplaudertes".
Erhältlich bei Ihrem Buchhändler oder - Springer Customer Service Center GmbH, Haberstrasse 7, 69126 Heidelberg, Germany / Call: + 49 (0) 6221-345-4301 / Fax: +49 (0)6221-345-4229 / Email:

customerservice@springer.com / Web: springer.com

$[1] €(D)$ sind gebundene Ladenpreise in Deutschland und enthalten 7\% MwSt; $€$ (A) sind gebundene Ladenpreise in Österreich und enthalten 10\% MwSt. CHF und die mit [2] gekennzeichneten Preise für elektronische Produkte sind unverbindliche Preisempfehlungen und enthalten die landesübliche MwSt. Programm- und Preisänderungen (auch bei Irrtümern) vorbehalten. Es gelten unsere Allgemeinen Liefer- und Zahlungsbedingungen.

Springer-Verlag GmbH, Handelsregistersitz: Berlin-Charlottenburg, HR B 91022. Geschäftsführung: Haank, Mos, Hendriks 